\title{
A MELANCOLIA E O MEMORIALISMO FICCIONALIZADO EM AUSTERLITZ, DE W. G. SEBALD ${ }^{1}$
}

\author{
Chimica Francisco ${ }^{2}$
}

Resumo: O presente artigo insere-se na perspectiva da Teoria da Literatura com foco em estudos de literatura contemporânea, no seu gênero romance. $O$ mesmo aborda a última obra do escritor alemão, W. G. Sebald, sobretudo no que diz respeito à melancolia, como também fazer uma breve incursão ao memorialismo patente nesse romance que parece mesclar a realidade com a ficção numa abordagem criativa e talvez mesmo inovadora no modo como o seu discurso é construído e como as personagens, num "diálogo" que tende mais para um monólogo entre o protagonista da obra Austerlitz (2008), Jacques Austerlitz, e o narrador que se encontram pela primeira vez na estação de comboios de Antuérpia e, subsequentemente em outras estações e sempre por acaso.

Palavras-chave: Melancolia, memorialismo, ficção, Austerlitz.

Abstract: This paper is part of an approach in Literary Theory perspective with focus in studies of contemporary literature, in the gender novel. It intends to bring a sight around the last work of the German writer W. G. Sebald, especially regarding to melancholy but also to make a short raid to memorialism patent in this novel that seems to mix reality and fiction in a creative approach and maybe indeed innovative in the way its speech is built and how the characters, in a game of dialogues that tends more to a monologue among the protagonist of the work Austerlitz (2008), Jacques Austerlitz, and the narrator that meet each other for the first time in the Antwerp train station, and subsequently, in other train stations, always by chance.

Key-words: Melancholy; memorialism; fiction; Austerlitz.

\footnotetext{
${ }^{1} \mathrm{O}$ presente trabalho foi realizado com apoio do Programa Estudantes-Convênio de Pós-Graduação PEC-PG, da CAPES/CNPq - Brasil.

${ }^{2}$ Professor na Universidade Pedagógica - Moçambique. Doutorando em Estudos Literários na UFSM. Bolsista do PEC-PG CAPES. E-mail: chimicafrancisco@yahoo.com.br
} 


\section{Introdução}

O livro Austerlitz começa com a seguinte passagem memorial:

$\mathrm{Na}$ segunda metade dos anos 60 , viajei com frequência da Inglaterra à Bélgica, em parte por motivo de estudos, em parte por outras razões que a mim mesmo não ficaram inteiramente claras, às vezes apenas por um dia ou dois, às vezes por várias semanas (SEBALD, 2008, p. 7).

O excerto remete para a lembrança de um fato anterior que servirá como ponto de partida para a narração que irá se movimentar entre o imaginado e a realidade, entre o biografismo (como quem conta a sua própria experiência, a sua vida e que com muito esforço se lembra dela) e o romance. Os carris das linhas férreas, duas linhas paralelas que nunca se cruzam, parecem simbolizar por um lado o protagonista Jacques Austerlitz, e, por outro lado o narrador que só têm a oportunidade de conversar a partir de um encontro ocasional, inesperado e até mesmo inexplicável e sempre em estações de linha férrea.

Note-se o exemplo seguinte:

Cerca de meia hora mais tarde, eu me achava sentado no bar do Great Eastern Hotel na Liverpool Street, à espera do próximo trem para casa. (...), percebi então subitamente, (...) uma figura solitária que não poderia ser ninguém mais senão Austerlitz, que eu não via, como me dei conta naquele instante, fazia quase vinte anos (SEBALD, 2008, p. 42-43).

É como se de uma aparição se tratasse o aparecimento quase do nada de Jacques Austerlitz ao narrador.

Assim, seguiu-se para a prossecução deste artigo, uma metodologia analítica e bibliográfica, com caráter qualitativo. E como objetivos pretende-se estudar, na obra Austerlitz, a melancolia e o memorialismo ficcionado, identificar e explicar as suas manifestações ao longo da obra, corpus deste artigo. O nosso interesse pela obra surge da admiração que nutrimos pelo seu autor, W. G. Sebald, que apresenta nas suas obras uma escrita peculiar, uma espécie de mistura de gêneros (entre o ensaio, a biografia e o romance) que, numa primeira impressão pode levar o leitor menos experimentado a uma 
leitura menos agradável e também menos prazerosa. É o que pode acontecer ao se ler Os Anéis de Saturno, outra obra do mesmo autor, que é um exemplo muito elucidativo de melancolia. Mas uma segunda e até mesmo uma terceira leitura aclarará e convidará o leitor a caminhar, e porque não a viajar de trem com o narrador nas suas peregrinações e junto com ele vivenciar as suas melancólicas e angustiantes lembranças.

Posto isto, coloca-se a seguinte questão de partida que orientará o presente artigo: como a melancolia e o memorialismo ficcionalizados se manifestam na obra Austerlitz, de W. G. Sebald?

\section{A Melancolia e o memorialismo ficcionalizado em Austerlitz, de W. G. Sebald}

A obra Austerlitz, de W. G. Sebald é um exemplo de uma nova dinâmica de escrita que abandona a narrativa com um narrador "puro" ou clássico, um narrador considerado como uma autoridade, detentor e relatador das suas experiências como o definiram Benjamin, Adorno e Rosenfeld. Essa visão de narrador tradicional, um narrador de confiança, que podia ser sedentário ou viajante, hoje, na era pós-moderna, tende a diluir-se como está evidente em Austerlitz ao misturar ficção, ensaio, biografismo, memorialismo exacerbado e romance.

A partir de finais do século XIX e, sobretudo depois das duas grandes guerras mundiais começa-se a pôr em questão a posição do narrador, pois com o desenvolvimento da ciência e da tecnologia e, mais tarde com os efeitos catastróficos, consequência das duas grandes guerras, a faculdade de narrar ficou mais distante do que se podia imaginar, como se pode testemunhar: "O narrador - por mais familiar que este nome nos soe - de modo algum conserva viva, dentro de nós, a plenitude de sua eficácia. Para nós ele já é algo distante e que ainda continua a se distanciar" (BENJAMIN, 1983, p. 57).

Uma experiência semelhante é trilhada por Vladimir Nabokov na sua obra Fogo Pálido, que faz uma fusão entre poema e seus comentários para daí resultar num romance diametralmente oposto ao romance tradicional. Podemos aqui depreender que os tradicionais gêneros textuais estão em decadência, é a revolução em direção a possíveis novos gêneros. 
A narrativa de W. G. Sebald, proporcionada em Austerlitz, caracterizada por um parágrafo longo, sem diálogo expresso nos moldes tradicionais em que o travessão assinala a fala da personagem é, de momentos em momentos interrompida por imagens e fotografias diversas que, no concreto, não estão aí colocadas com alguma função de explicar e ou dar sequência ao texto. Apenas a expressão "... disse Austerlitz" que percorre toda a narrativa é que marca uma espécie de diálogo entre o protagonista e o narrador, excetuando alguma, mas raríssima intervenção de Austerlitz de modo diferente, por exemplo: “... assim começou Austerlitz em resposta..." (SEBALD, 2008, p. 13).

Outro aspecto a ter em consideração são as imagens que aparecem ao acaso, embora em alguma ocasião se faça a sua menção no texto escrito. Em um artigo Cademartori ${ }^{3}$ chega a afirmar que:

As fotografias estão fora de foco e em precárias condições de reprodução. Imprecisas, escuras, com contrastes mal resolvidos, elas são sombras que acompanham o empenho em recuperar o passado. Ao manejar a câmera, Austerlitz costumava fazer perquirições sobre o tempo.

Aí repousa a melancolia da personagem Austerlitz que, personificada no próprio Sebald, que apossado pelas lembranças do seu passado vai escrevendo quase que ininterrupta e automaticamente num discurso de angústia, tormento e melancolia. E, do mesmo modo, ao longo do livro vão sendo apresentados desenhos, mapas, fotografias, algumas vezes muito próximos uns dos outros, como nos exemplos das páginas 186, 188-193, e, outras vezes, distanciados por longos trechos de texto escrito que são, na verdade, a essência da obra e não as diversas imagens sucessivamente encaixadas quase que aleatoriamente.

Jacques Austerlitz, o personagem protagonista da obra Austerlitz,é um professor de Arte e Literatura e também muito apaixonado pela História da Arquitetura. Tinha em 1967, segundo o narrador, "uma aparência quase jovial, com cabelos loiros curiosamente ondulados..." (SEBALD, 2008, p. 11). Tanto no primeiro encontro com o narrador, em Antuérpia, assim como em todos os

\footnotetext{
3 CADEMARTORI, Ligia. Escritor e literatura em outro lugar. Antares - Letras e Humanidades. Disponível em:www.ucs.br/etc/revistas/index.php/antares/.../1157, acessado em 05 de jun. de 2014.
} 
que se seguiram, Austerlitz trazia sempre a mesma indumentária: "Naquele dia em Antuérpia, como em todos os nossos encontros posteriores, Austerlitz usava pesadas botas de caminhada e um tipo de calça de operário feita de chita azul desbotada, bem como uma jaqueta talhada por alfaiate,..." (SEBALD, 2008, p. 11).

Austerlitz começa a reconstruir as suas lembranças quando se encontra com Vera Rysanová, uma senhora que fora vizinha e que havia ajudado sua mãe a cuidar dele. Vera reativa a memória de Austerlitz através de um relato de inúmeros fatos ocorridos antes e até a partida forçada de Austerlitz de Praga. Austerlitz, ainda muito novo, com cerca de cinco anos, em 1939 é embarcado pela mãe num comboio que rumaria para Londres, com o fim de poupá-lo da situação de guerra eminente no seu país. Ele, Austerlitz ficou posteriormente sabendo que seus pais, por força das circunstâncias, haviam sido separados, o pai conseguira exílio na França, em Paris e a mãe junto a outros milhares de pessoas fora levada para Terezin: "Ele próprio sabia apenas que o casal Elias me havia acolhido em sua casa no início da guerra, quando eu era ainda criança pequena, e por isso não podia me dizer nada mais preciso" (SEBALD, 2008, p. 70).

O casal Elias dera-Ihe como nome Dafydd Elias, mas depois, aos 15 anos de idade, através do diretor da escola, Penrith-Smith, Austerlitz descobre a sua verdadeira identidade e também que ele havia nascido em Praga: "Antes, porém, era seu dever comunicar-me que nos meus exames eu deveria assinar, não Dafydd Elias, mas Jacques Austerlitz" (SEBALD, 2008, p. 70).

A partir de então, Austerlitz faz uma digressão em busca do seu próprio passado para tentar, através da memória e das suas lembranças, reconstruir a sua identidade. Então, parte para Praga, a terra de sua primeira infância, “... eu mal pusera os pés em Praga e já encontrara o local da minha primeira infância, do qual, até onde podia lembrar, se apagara toda a memória" (SEBALD, 2008, p. 150). Essa tentativa que Auterlitz faz de procurar remeter a sua mente ao seu passado, para puxar forçosamente fatos de sua infância, é sintomático da melancolia.

Austerlitz lembra-se de quando esteve aos cuidados do casal Elias desde que chegara de Praga ainda criança, lembra-se também da morte de Gwendolyn na casa do pregador em Bala, lembra-se igualmente do frio que 
fazia nessa mesma casa em quase todas as estações do ano, lembra-se do seu sucesso na escola em que fora considerado como melhor aluno, o que causara admiração ao professor André Hilary que lhe havia atribuído nota $A$ com três estrelinhas. Fora esse mesmo professor Hilary que lhe dissera que 0 seu nome Austerlitz, segundo a história, estava associado ao glorioso povo francês: "Quando trago hoje à memória os relatos de André Hilary, disse Austerlitz, torno a lembrar da ideia que me surgiu então, de estar ligado de alguma forma misteriosa ao passado glorioso do povo francês" (SEBALD, 2008, p. 75).

As lembranças bastante tortuosas e as desenfreadas e esforçadas tentativas de sempre voltar para o passado, na sua profundidade, e trazer à memória presente todos os traumas passados como consequência de um passado histórico hediondo que tem paralelo com o trauma de todo um povo do qual Austerlitz faz parte, o que confunde a sua vida e história com a história da sua pátria devastada pela guerra, onde as populações foram obrigadas a se refugiarem como foi o caso de seu pai, exilado em Paris, e o de Austerlitz, ainda criança, entregue à sua própria sorte, colocado por sua mãe dentro de um comboio com destino ao país de Gales para o salvar dos horrores da guerra iminente. Outras como foi a sorte de sua mãe, foram levadas para os campos de concentração.

Austerlitz tem em quase todas as suas buscas pela memória lembranças muito vagas, nada é garantidamente certo, o que é agravado com a queda que teve e que o deixou em coma por um período de três semanas como testemunha a seguinte passagem da obra:

... quando caí a caminho do quiosque no final da Alderney Street, batendo a cabeça no meio-fio, dei entrada no Hospital St. Clement's ao cabo de uma série de diversos ambulatórios e prontos-socorros, e ali me encontrava em uma das alas masculinas quando voltei a mim, após finalmente sair de um coma que, como me explicaram mais tarde, durou quase três semanas e paralisou, não as funções corporais, mas todos os processos mentais e todas as emoções (SEBALD, 2008, p. 225).

Nesse processo de reconstrução de sua identidade há mais um trauma que vem dificultar ainda mais essa empreitada, é a melancolia em que a 
pessoa está com as emoções paralisadas. Fica, assim, privado de "todos os processos mentais e todas as emoções", triste ironia do destino, todos os acessos à memória ficam temporariamente bloqueados, fica sem sentido de vida. Há neste sentido um esquecimento forçado pela circunstância do acidente. Isso faz lembrar o cerco à cidade de Antuérpia (SEBALD, 2008, p. 21), que dificilmente resistia às investidas do armamento inimigo e quanto mais se melhorava a arquitetura para a resistência do cerco, mais o inimigo sofisticava o seu armamento e quanto mais se estendia o cerco através de extensão de seu raio ou de seu perímetro para melhor segurança da cidade, mais o inimigo se interessava em descarregar as suas investidas sobre ela até que se compreendeu que não havia fortificações nem homens/ soldados suficientes para uma guarnição que seria de desejar.

Assim, as memórias ainda que Austerlitz se empenhasse em reconstruir a sua história e, como ficou dito, história essa que se confunde, ou melhor, que tem um paralelismo com a história de todo um país, o seu, essa mesma história ficaria entre lembranças e ainda muitas outras lembranças não totalmente lembradas sobre os diversos traumas, sobre o holocausto que é outra melancolia em que as lembranças de Austerlitz levam sempre a pensar muito em morte ou em outras pessoas que morreram ou até mesmo em sua própria morte.

Na obra Austerlitz, de W. G. Sebald a memória simboliza essa busca desenfreada, essa busca constante desencadeada pelo personagem Austerlitz do seu passado para, a partir dele poder reconstruir a sua própria identidade e uma estrutura de suporte para a sua vida, pois cedo perdeu a estrutura familiar (ao ser violentamente separado dos seus pais) e também perdera o seu próprio nome, elementos que julgamos importantes para a construção e a formação inicial do indivíduo.

Como ficou exposto, na obra encontramos diversas imagens, fotografias, mapas que à partida remetem para espaços (zoológicos, edifícios de hospital, muros, fortificações), fotografias de pessoas (a do próprio Austerlitz enquanto criança ainda aos cinco anos de idade) que de fato existiram, mapas de lugares reais, que tudo isso leva para uma situação de realidade, no entanto fica claro que o seu uso na obra é fictício, igualmente compreende-se que a personagem que parece tão real e que ao longo da obra sufoca a presença do narrador em 
toda a narrativa, ou se confunde com ele e até com o próprio autor da obra, Austerlitz não existiu. Assim, a obra toda ela é uma ficção que procura, ao longo da sua construção, mesclar o memorialismo que se confunde com o biografismo e com o ensaio.

\section{Conclusão}

A obra Austerlitz, de W. G. Sebald é um poço de mistérios que ainda precisa de muitas e variadas leituras que possam pouco a pouco trazer uma luz do fundo do túnel. Sebald ao construir a sua história não só quis trazer à superfície os problemas como tendo afetado apenas a personagem que é o protagonista, Austerlitz, como pessoa singular durante o período da segunda Guerra Mundial (em particular o holocausto judeu de 1939 até 1945) e depois desta, mas também os problemas de toda a Alemanha, seu país que fora devastado e reduzido em amontoados e lamentáveis escombros.

A memória que é um exercício doloroso no sentido de trazer maior parte de lembranças senão todas do passado para o presente, Sebald fá-lo com ajuda de imagens, de fotografias e de mapas que lembram algumas situações, pessoas e espaços reais, mas que são transformados em história, aliás o recurso à própria história da Alemanha no período da segunda grande guerra é outra estratégia seguida por Sebald nessa empreitada que faz confundir a realidade com a não realidade, construindo uma ficção.

\section{REFERÊNCIAS}

BENJAMIN, Walter. O narrador. Observações acerca da obra de Nicolau Leskow. In: BENJAMIN et al. Os pensadores. São Paulo: Abril Cultural, 1983.

CADEMARTORI, Ligia. Escritor e literatura em outro lugar. Antares - Letras e Humanidades. Disponível em: www.ucs.br/etc/revistas/index.php/antares/.../1157, acesso em 05/06/2014.

SEBALD, W. G. Austerlitz. Trad. José Marcos Macedo. São Paulo: Companhia das Letras, 2008. 